Imágenes en Urología

\title{
Incontinencia y urgencia urinaria en mujer adulta
}

\author{
Juan J. Espejo Herrero, Ana Higuera Higuera, Victoria Palomo Gallego, $\mathrm{M}^{\mathrm{a}}$ Teresa Jaén Reyes, \\ Rocío Díaz Aguilera, Antonio Uceda Vaño*
}

Servicio de Radiodiagnóstico. Servicio de Cirugía General*. Empresa Pública Hospital Alto Guadalquivir. Andújar. Jaén, España

$\mathrm{M}^{\mathrm{s}}$ ujer de 69 años que acude a urgencias derivada por su médico de atención primaria por incontinencia y urgencia miccional de reciente aparición y masa pélvica en ecografia.

Tras la valoración en el servicio de urgencias se le realizó una ecografía abdominopélvica donde se apreció una hidronefrosis del riñón derecho provocada por una masa retroperitoneal que infiltraba al riñón y uréter derechos y se continuaba con un engrosamiento difuso de la pared de la vejiga. Posteriormente se realizó una TC torácica abdominal y pélvica objetivando los hallazgos descritos en la ecografía, una lesión lítica en la octava costilla derecha con masa de partes blandas asociada y varias adenopatías de aspecto patológico localizadas en espacio retrocrural izquierdo, mesenterio y cadenas iliaca y axilar izquierdas.

Se biopsiaron los ganglios axilares y la masa de partes blandas costal obteniendo el resultado anatomopatológico de transformación a linfoma difuso de células grandes B de un linfoma folicular. Estadio IV.

Tras el diagnóstico la paciente inició tratamiento con quimioterapia, tres meses después en el control de TC habían desparecido las adenopatías y la lesión costal, persistiendo la masa retroperitoneal, aunque con una importante disminución de su tamaño.

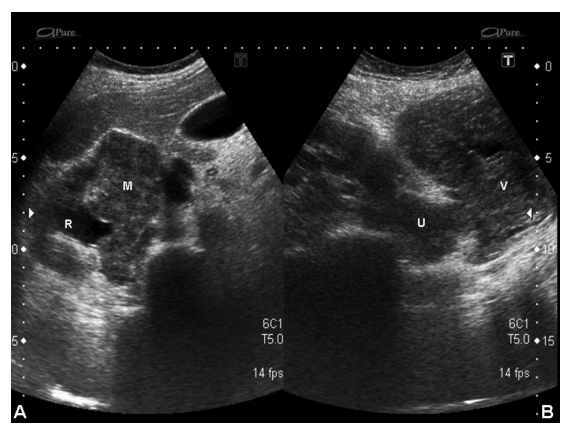

FIGURA 1. A: corte ecográfico a nivel del riñón derecho $(R)$, que presenta una hidronefrosis provocada por la infiltración de su parénquima y pelvis por una masa retrope ritoneal (M). B: corte ecográfico a nivel de la desembocadu. ra del uréter derecho (U) en la vejiga (V), donde se aprecia un marcado enrecia un marcado pared de ambos.

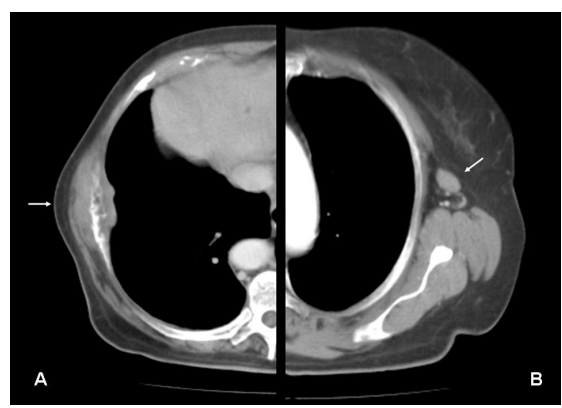

FIGURA 2. A: corte de TC torácica en fase arterial donde se apre. cia una lesión litica de la octava costilla dere. cha con masa de partes blandas asociada fle. cha blanca).

B: corte de TC torácica a corte de TC torácica a nivel axilar izquierdo donde se visualiza una adenopatía patológica
de $2 \mathrm{~cm}$. de diámetro (flecha blanca).

\section{REFERENCIAS RECOMENDADAS}

- Imaging of Renal Lymphoma: Patterns of Disease with Pathologic Correlation. Sheth S, Ali S, Fishman E. RadioGraphics 2006;26:1151-1168.

- Renal Lymphoma: CT Patterns with Emphasis on Helical CT. Urban B, Fishman E. RadioGraphics 2000;20:197.

- Primary renal lymphoma: a rare neoplasm that may present as a primary renal mass. Ahmad AH, MacLennan GT, Listinsky C. The Journal of Urology 2005;173(1):239-239. - Lymphoma presenting as a solitary renal hilar mass. Chang, SS. Kayak, R. Cookson, MS. Urology 2002;59(1):134-135.

- Linfoma renal primario en paciente con gammapatía monoclonal IgM O. Rodríguez Faba,J.M, Fernández Gómez JL, Martín Benito L, Parra Muntaner AM, Gutiérrez Palacios J, García Rodríguez A, Jalón Monzón J, Regadera Sejas. Actas Urol Esp 2004;28(5):396-398.

- Linfoma No Hodgkin B de célula grande primario de vejiga. Presentación de un caso. Álvarez Álvarez C, Vieites Pérez-Quintela B, Pesqueira Santiago D, Santos Armentia E, San Miguel Fraile P, Antón Badiola I. Actas Urol Esp 2005; 29 (8): 902-904.

- Linfoma renal primario.Torrecilla García-Ripoll JR, Pascual Samaniego M, Martín Blanco S, Rivera Ferro J, Peral Martínez JI, Fernández del Busto E. Actas Uro Esp.2003;27(7):555-558.

Correspondencia autor: Dr. Juan J. Espejo Herrero

Servicio de Radiodiagnóstico. Hospital de Alta Resolución del Puente Genil Miguel Quintero Merino, s/n Polígono Industrial Las Acacias

14500 Puente Genil - Córdoba. Tel.: 957615000

E-mail autor: juanjoseespejo@gmail.com

Información artículo: Imágenes en Urología

Trabajo recibido:septiembre 2007

Trabajo aceptado: octubre 2007

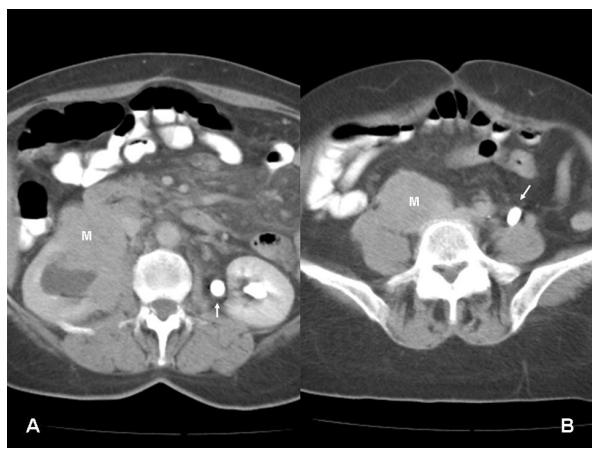

FIGURA 3.- A: corte de TC abdominal en fase pielográfica donde se objetiva el riñón derecho hidronefrótico que no presenta eliminación del contraste IV infiltrado por una masa retroperitoneal (M) y el riñón izquierdo de caracteristicas normales con la pelvis $y$ el uréter contrastados por la eliminación del contraste inv. (flecha blanca).

B: corte de TC pélvica en fase excretora donde apreciamos el uréter derecho infiltrado $y$ engrosado (M) y el uréter izquier do contrastado de caracteristido contrastado de caracteristi-
cas normales (flecha blanca).

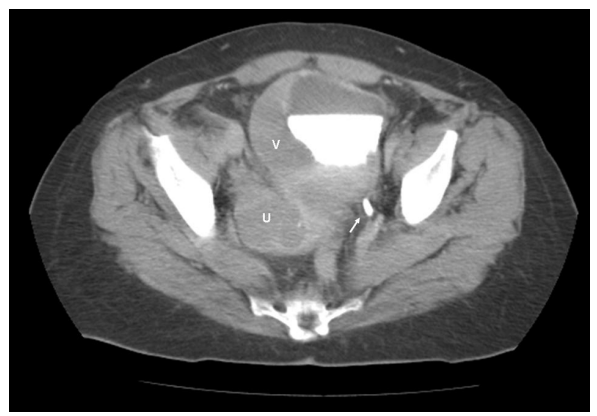

FIGURA 4.- corte de TC pélvica en fase excretora en el que se visualiza el uréter derecho infiltrado (II) dese decho infltrado (U) desembocando en una vejiga infiltrada de pared engrosada (V) con contraste en su interior. Uréter izquierdo antes de desembocar en la vejiga (flecha blanca). 